\begin{tabular}{|c|c|c|c|c|}
\hline $\begin{array}{c}\text { - от участия в уставных капиталах других } \\
\text { организаций }\end{array}$ & - & 186797535 & 333897776 & - \\
\hline Платежи - всего, в том числе: & 106461714 & 112878155 & 117856055 & 110,7 \\
\hline $\begin{array}{c}\text { - поставщикам (подрядчикам) за сырье, материаль, } \\
\text { работы, услуги }\end{array}$ & 34203351 & 36087022 & 35646957 & 104,2 \\
\hline - в связи с оплатой труда работников & 14745758 & 29871231 & 15947834 & 108,1 \\
\hline - прочентов по долговым обязательствам & 37495745 & 32725065 & 54974723 & 146,6 \\
\hline - налога на прибыль организации & 11639376 & 6850119 & 5157488 & 44,3 \\
\hline -прочие платежи & 8377484 & 7344718 & 6129053 & 73,6 \\
\hline $\begin{array}{c}\text { Сальдо денежных потоков от инвест } \\
\text { операций }\end{array}$ & 898017703 & 1376163426 & 1549054223 & 172,4 \\
\hline
\end{tabular}

Из данных таблицы 3 можно увидеть, что денежный поток к 2020 году стал положительной величиной, что произошло за счёт роста поступления денежных средств на 65,9\% от арендных платежей, лицензионных платежей, комиссионных платежей и прочих платежей.

Для повышения инвестиционной привлекательности предлагаю следующие мероприятия.

1. покрытие долгосрочных и краткосрочных продуктов для создания положительной кредитной истории.

2. разработка проекта для нефтегазовой отрасли, которая предполагает учитывать экологическую составляющую для нейтрализации последствий окружающей среды данных проект послужит для роста и инвестиционной привлекательности и имеет следующие преимущества:

- не требует больших дополнительных затрат для сбора экологической информации;

- дают возможность проведения объективной сравнительной оценки инвестиционного проекта на основе других проектов и их численной характеристики [5].

Таким образом предложенные рекомендации позволят повысить инвестиционную привлекательность предприятия и увеличат финансовое состояние.

$$
* * *
$$

1. Бабенко, И.В. Пути повышения инвестиционной привлекательности предприятия // Вестник науки. - 2020. №10(31). - C.28-38.

2. Рахматуллин Ю.Я. Экономический анализ финансовых результатов от продажи продукции на примере сельскохозяйственных организаций: монография / Ю.Я. Рахматуллин. - СПб: Свое издательство, -2016. $163 \mathrm{c}$.

3. Рахматуллин Ю.Я. Оценка резервов и прогнозирование окупаемости затрат в АПК // АПК: Экономика, управление. - 2017. - № 2. - С. 36-42.

4. Сулейманов, Д.А. Инвестиционная привлекательность предприятия: критерии оценки и направления анализа // Региональная экономика: проблемы и перспективы развития. - 2016. - С.149-153.

5. Хабиров Г.А., Рахматуллин Ю.Я., Байков А.Е. Рентабельность производства - основа финансовой устойчивости сельхозпредприятий // Аграрная наука. - 2002. - № 8. - С. 4-5.

\title{
Гартман Д.С. \\ Повышение эффективности управления предприятием при помощи информационных и коммуникационных технологий
}

Кубанский государственньй аграрньй университет имени И.Т. Трубилина doi: 10.18411/trnio-11-2021-97

(Россия, Краснодар)

\section{Аннотация}

В данной статье дается определение предприятия. Рассмотрены его виды и особенности, а также влияние информационных и коммуникационных технологий на эффективность управления предприятием. 
Ключевые слова: эффективность управления, информационные технологии, коммуникационные технологии, предприятие, повышение эффективности.

\section{Abstract}

This article provides a definition of an enterprise. Its types and features are considered, as well as the influence of information and communication technologies on the efficiency of enterprise management.

Keywords: management efficiency, information Technology, communication technologies, company, increased efficiency.

Предприятие - это самостоятельный, организационно-обособленный хозяйствующий субъект, который обладает правами юридического лица, осуществляет производство и сбыт товаров, а также выполнение работ и оказание услуг. При нынешних обстоятельствах, предприятие - это основное звено в рыночной экономики т.к. на данном этапе производятся востребованные обществом товары и происходит оказание необходимых услуг. Если рассматривать предприятие как юридическое лицо, то у него есть право осуществлять любую хозяйственную деятельность, но при условии, если она не запрещена законодательством и соответствует типу и целям созданного предприятия, а также предусмотрена в уставе. Каждое предприятие обладает собственным самостоятельным балансом, расчётным и другими банковскими счетами, а также печатью со своим брендом.

Систематизация различного рода предприятий происходит при выделении следующих факторов, соответствуя которым образуются следующие группы: отрасль, используемые ресурсы, структура производства, форма собственности, организационно-правовая форма, масштаб предприятия, местоположение, национальная собственников. По форме собственности предприятия бывают: частные, общественные, государственные, муниципальные. В плане масштабов предприятия могут быть малыми, средними и крупными. Принадлежность предприятия к каждому из масштабов определяется такими факторами, как: число работников, годовой финансовый оборот, основной капитал, количество рабочих мест, зарплата работников, использование исходных материалов. По организационно-правовой форме предприятия бывают индивидуальные, партнёрские и корпорации. Цели предприятия могут быть коммерческими и некоммерческими. По отраслевому признаку предприятия бывают: промышленными, которые занимаются производством товаров общего назначения; торговыми, которые не занимаются производством товаров, но являются поставщиками; транспортными; предприятия в сфере услуг, оказывающие различного рода услуги; занимающиеся оказанием финансовых услуг; страховыми, занимающиеся страхованием от разного рода несчастных случаев.

Эффективное управление предприятием требует использование всех технических, экономических, организационных и социальных ресурсов, чтобы достичь главной цели удовлетворение разного рода потребностей общества широким ассортиментом товаров и услуг. Предприятие имеет свою собственную систему управления, состоящую из управленческой и управляемой подсистем. Управленческая подсистема состоит из органов управления, а управляемая из коллектива, который осуществляет производственнохозяйственную деятельность предприятия.

В наши дни экономика неразрывно связана с информационными и коммуникационными технологиями, развитие и прогресс которых оказывают непосредственное влияние на эффективность управления предприятием. Само предприятие, в свою очередь, наращивает капитал при помощи продукции, имеющей информационную ценность, а также определяет состояние общества и экономики. Информация стала настолько же значимой, как и финансовые, материальные и энергетические ресурсы. Информационные и коммуникационные технологии, а также их развитие в различных экономических сферах является основным показателем того, что осуществляется активный переход информационной экономике. 
Для повышения эффективности производства предприятие вынуждено урезать время выделенное на принятие решений, что повышает скорость обработки и передачи информации при использовании новейших технологий. Предприятие само себя обеспечивает информационными ресурсами с помощью информационно-коммуникационных технологий, которые содержат информацию об основных бизнес-процессах. Определение информационно-коммуникационных технологий является сочетанием двух независимых друг от друга процессов: информационные технологии и коммуникации. Поэтому создание методов повышения эффективности управления предприятием на их основе - одна из первостепенно важных и актуальных задача.

Информационные технологии - сочетание технических и программных средств, а также производственных процессов и методов, обеспечивающих сбор, хранение, обработку, анализ, выводы и распространение информации для снижения нагрузки из-за использования информационных ресурсов. Цель информационных технологий - оптимизация применения информационных ресурсов.

Коммуникация - это общение, взаимообмен информацией и рассуждениями друг с другом. Коммуникация - это социальный процесс, отражающий общественное устройство и выполняющий объединяющую функцию. Коммуникация подразделяется на два вида: семантическая и транспортная. Социальная коммуникация может происходить на трёх этапах: между субъектами, групповой и массовый.

По виду деятельности коммуникации подразделяются на три типа, в зависимости от поставленных целей: субъект-субъектные - равноправные взаимоотношения; субъектобъектные - характеризуются такими признаками, как: обучение, внушение и приказы; объект-субъектные - самоорганизация. Очень важно поподробнее изучить процесс взаимодействия нескольких субъектов на основе модели линейной коммуникации. При ее более детальном рассмотрении можно выделить три следующие составляющие: передающая - коммуникант; передаваемая - объект; принимающая - реципиент.

Для повышения эффективности коммуникационной системы необходимо уменьшить количество помех, которые оказывают негативное влияние на передачу информационных сообщений посредством их дублирования, а также применить по отношению к ним кодирование. Данная модель упрощена и является однонаправленной. Поэтому в ней есть своими недостатками: не ведется учет определенных свойств; не учитывает тот факт, что коммуникация - более сложный процесс, который осуществляется большим количеством субъектов, которые непосредственно влияют друг на друга.

При изучении сути управления коммуникацией предполагается, что субъект и объект считается целостной системой. Этот метод сочетает в себе два вида управления: людьми и средствами коммуникации. Управление коммуникационными средствами - контроль взаимодействия индивидов, которые управляют данными средствами. Такая управленческая система выполняет следующие функции: мотивация, контроль, организация, планирование и учет.

Объединение коммуникационных и информационных технологий образовало термин - информационно-коммуникационные технологии или ИКТ. Изучение данных технологий, заставляет обратить внимание на такие процессы, как хранение и обработка информации, коммуникационные, отвечающих за связь между предприятием и потребителем.

Анализируя сущность информационных технологий, приходим к выводу, что в нынешних обстоятельствах информационные технологии являются очень эффективным инструментом управления предприятием, а их цель - оптимизация использования ресурсов представляющих информационную ценность для организации.

Коммуникация является социальным явлением, которое описывается как культура отношений между субъектами, канал связи, технологическая сторона, сфера деятельности, процесс, функция, система, услуга. Основной составляющей модели коммуникаций является канал передачи данных, обеспечивающий отправку материального сообщения во времени и пространстве. 
Вывод: При объединении коммуникационных и информационных технологий образовался термин «информационно-коммуникационные технологии». При изучении влияния информационных трендов на информационно-коммуникационные технологии показало, с их помощью особое внимание уделяется коммуникационным процессам, которые отвечают за взаимодействие потребителей и их информационное обслуживание.

$$
* * *
$$

1. Осенний В.В., Трубилин М.Е. Современные информационные технологии в системе точного земледелия // Научное обеспечение агропромышленного комплекса. Сборник статей по материалам X Всероссийской конференции молодых ученых, посвященной 120-летию И.С. Косенко. Отв. за вып. А. Г. Кощаев. - 2017. C. $442-443$.

2. Информационные ресурсы и технологии в экономике: Учебное пособие / Под ред. Романова А.Н.. - М.: Вузовский учебник, 2018. - 319 с.

3. Ивасенко, А.Г. Информационные технологии в экономике и управлении: Учебное пособие / А.Г. Ивасенко, А.Ю. Гридасов, В.А. Павленко. - М.: КноРус, 2018. - 288 с.

4. Коршунова, Е.Д. Экономика, организация и управление промышленным предприятием: Учебник / Е.Д. Коршунова, О.В. Попова, И.Н. Дорожкин. - М.: Курс, 2018. - 272 с.

5. Краскова А. А. Оценка инвестиционной привлекательности предприятий АПК с использованием информационных технологий / А. А. Краскова, В. В. Осенний, Н. М. Гудимова // Научно-методический электронный журнал Концепт. - 2015. - № 6. - С. 31-35.

\section{Дружинин П.В. \\ Концентрация ресурсов в столице региона и ее последствия}

Карельский научный изентр РАН (Россия, Петрозаводск)

doi: 10.18411/trnio-11-2021-98

\section{Аннотация}

В статье исследуется влияние концентрации ресурсов в столице региона на развитие экономики региона в целом. Проблема состоит в том, что переток населения, в первую очередь молодежь, в столицу региона позволяет ей более успешно развиваться, но одновременно периферия теряет наиболее качественный человеческий капитал. Изучалась взаимосвязь показателей, характеризующих концентрацию населения в столице региона и развитие экономики региона в целом. Показано отсутствие положительного влияния концентрации населения в столице региона на основные показатели региональной экономики.

Ключевые слова: рост экономики региона, столица региона, концентрация населения.

\section{Abstract}

The article examines the influence of the concentration of resources in the capital of the region on the development of the region's economy as a whole. The problem is that the flow of the population, primarily young people, to the regional capital allows it to develop more successfully, but at the same time the periphery is losing the highest quality human capital. The interrelation of indicators characterizing the concentration of the population in the capital of the region and the development of the regional economy as a whole was studied. The absence of a positive influence of the concentration of the population in the capital of the region on the main indicators of the regional economy is shown.

Keyword: regional economic growth, regional capital, population concentration.

Столицы большинства российских регионов успешно развиваются, в то время как периферия этих регионов теряет ресурсы, в первую очередь человеческий капитал. Население, в первую очередь молодежь переезжает в столицу своего региона или более 